p 534/12). Tal tradução pode ser acessada através do seguinte endereço eletrônico: www.unicamp.br/cemarx/criticamarxista/critica20-A-althusser.pdf

4. Cf. MORFINO 6: "Althusser parece repetir a interpretação gramsciana de Maquiavel como teórico do Estado nacional. Esta repetição tem na verdade a função precisa de opor-se a filosofia da história, de romper o jogo de espelhos entre príncipe e partido fundado pela teleologia" (Minha tradução).

5. Utilizamos aqui a tradução de Márcio Bilharinho Naves para a Revista Outubro $n^{\circ}$ 20. Para que o leitor possa consultar nossas referências textuais nesta tradução brasileira, colocaremos após a página do original em francês a página da tradução brasileira em itálico ( Ex: ALTHUSSER 4, p. 285-286 / 65). A tradução em português pode ser acessada na internet pelo seguinte link: www.revistaoutubro.com.br/ edicoes/02/out2_05.pdf.

\section{DUAS LEITURAS DO CAPITALISMO EM MARX}

Renan Gonçalves Rocha**

Resumo: A compreensão piramidal do sistema capitalista em Marx, isto é, a concepção que estabelece a determinação da base econômica sobre a superestrutura (direito, Estado e ideologias) foi uma formulação bastante difundida pela teoria athusseriana. Não obstante, essa compreensão piramidal do capitalismo negligencia o papel determinante do aparato jurídico-político sobre os processos econômicos. Dessa forma, pretende-se mostrar que na relação entre economia e Estado em Marx há co-determinação, e não uma determinação unidirecional da economia sobre o Estado.

Palavras-chave: Althusser, Marx, Estado, economia, determinação, co-determinação.

Há uma análise do capitalismo atribuída a Marx, que estabelece que os processos socioeconômicos determinam de forma unidirecional o aparato jurídico-político. É uma compreensão piramidal do capitalismo, na qual a infraestrutura econômica determina a superestrutura jurídicopolítica e a ideológica. Tal analise do capitalismo foi atribuída a Marx tanto por teóricos marxistas (como Louis Althusser ${ }^{1}$ ), quanto por estudiosos não marxistas (como Norberto Bobbio ${ }^{2}$ ).

* Este texto foi apresentado com o título Uma reflexão crítica sobre o edifício social em Althusser. Por considerar que não é propriamente uma crítica ao pensamento de Althusser, mas uma releitura de Marx (partindo, de certa forma, de Althusser) decidimos mudar o título do texto.

**Renan Gonçalves Rocha (renangrocha@yahoo.com.br) é mestre em filosofia pela Universidade Federal de Goiás (UFG) e professor do Instituto Federal de Goiás (IFG). 
No entanto, ao examinar a obra O Capital, o Estado capitalista (aparato jurídico-político) não aparece apenas e tão-somente como determinado pela economia. Distintamente da leitura de Althusser e Bobbio acerca da relação entre a economia e o Estado capitalista em Marx, este aparece também como determinante da economia.

Vejamos o que Marx diz em $O$ Capital ao analisar os casos do desenvolvimento do capitalismo alemão e francês no período de JeanBaptiste Colbert, que ocupou um dos cargos mais importantes, o de ministro das finanças, no governo de Luis XIV no século XVII:

O mínimo da soma de valor que deve dispor um possuidor individual de dinheiro ou mercadorias para metamorfosear-se em capitalista varia em diferentes graus de desenvolvimento, é diferente nas diferentes esferas de produção, conforme as condições técnicas específicas de cada uma. Certas esferas de produção exigem já nas primeiras etapas da produção capitalista um mínimo de capital que ainda não se encontra em mãos de indivíduos isolados. Isso leva, em parte, o Estado a subsidiar tais particulares, como na França no tempo de Colbert, e em alguns Estados alemães até a nossa época, em parte à constituição de sociedades como monopólio legal para explorar determinados ramos industriais e comerciais (Marx 6, p. 234).

Essa análise do pensador alemão é importante para explicitar que o desenvolvimento econômico capitalista, desde seu surgimento, utiliza o Estado para que possa tornar-se uma economia ampla, no sentido de expandir para vários setores produtivos. Portanto, Marx contribui para esclarecer que a economia capitalista depende do Estado para existir e se desenvolver, em vários ramos da produção.
Em outro momento de $O$ Capital, a mesma ideia é desenvolvida, porém não mais partindo dos exemplos francês e alemão, mas do exemplo britânico. Explica Marx: "A influência [...] da Inglaterra no mercado mundial, uma influência que, ao que parece, não decorre das leis naturais da produção capitalista, torna necessária a intervenção do Estado, a saber, a proteção daquelas leis da natureza e da razão pelo Estado" (Marx 6, p.142).

Isto é, o desenvolvimento da economia capitalista, que é considerado um desenvolvimento natural por alguns pensadores liberais, não tem a naturalidade que eles proclamam. Sem a intervenção do Estado moderno capitalista, não se poderia universalizar o sistema do capital. Consequentemente, não se poderia falar de capital global, muito menos de mercado mundial, conceitos indispensáveis na compreensão do capitalismo contemporâneo. A expansão capitalista para além das fronteiras nacionais tem como pré-requisito a intervenção do Estado capitalista moderno.

A dinâmica produtiva do capital, como falavam Adam Smith e Marx, é uma produção em escala sempre ampliada (Smith 8, p. 15). Por isso, o sistema capitalista não poderia manter-se como um modelo produtivo reduzido aos limites das fronteiras nacionais. O imperativo capitalista de produzir sempre mais implica a busca de novos mercados, fora dos limites nacionais.

Os limites nacionais, ou melhor, os limites do mercado nacional são insuficientes para que os consumidores comprem toda a produção das unidades produtivas que estão alocadas em uma determinada nação. Por conseguinte, a produção capitalista, com o imperativo de produzir em escalas sempre maiores - uma vez que esta é a possibilidade de obter lucros também sempre ampliados -, recorre à intervenção do Estado capitalista na esfera internacional. Recorrer ao Estado é uma condição indispensável para a continuidade da produção e a reprodução sempre ampliada de mercadorias. 
É o Estado capitalista o responsável pela ampliação de novos mercados para os produtos de unidades produtivas que estão dentro de suas fronteiras. Dessa forma, ele assume a posição não só de interventor para a expansão de novos mercados, mas também de protetor das mercadorias nacionais.

Para Marx, a economia capitalista, desde suas primeiras fases, tem como co-determinante, e base de sua existência, o Estado capitalista. No entanto, não se pode esquecer que o Estado capitalista também tem como co-determinante, e base de sua existência, a economia capitalista. Portanto, a relação entre economia e Estado capitalista em Marx não é, como pensam Althusser e Bobbio, uma questão de determinação unidirecional. A relação entre ambos não é um movimento mecânico, no qual a economia impulsiona o surgimento e o funcionamento do Estado.

A íntima relação entre Estado e economia no capitalismo parece ser mais adequadamente pensada em termos de co-determinação. E, nesse caso, a temporalidade não é a do antes e depois. Para Marx, o que está em questão não é se o Estado moderno é anterior à economia capitalista ou o inverso. Quando se pensa em termos de co-determinação, a simultaneidade está no âmago (temporal) da relação entre Estado e economia.

O Estado moderno não pode, por conseguinte, ser compreendido de maneira simplista, como uma superestrutura determinada pela economia, uma vez que sua ação pertence à própria base material do paradigma produtivo do capital. Isto é, para o filósofo alemão não há economia capitalista sem Estado capitalista, e não há Estado capitalista sem economia capitalista.

$\mathrm{Na}$ verdade, o Estado moderno pertence à materialidade do sistema do capital e corporifica a necessária dimensão coesiva de seu imperativo estrutural orientado para a expansão e para a extração do trabalho excedente. É isto que caracteriza todas as formas conhecidas do Estado que se articulam na estrutura da ordem sociometabólica do capital (Mészáros 7, p.121).

Outro fator importante, quando se abandona a perspectiva do Estado como uma superestrutura, é que Estado e a economia capitalista, como elementos distintos de uma mesma base (a base material do sistema do capital), não só se determinam mutuamente, mas também, como elementos distintos, podem se contradizer, ${ }^{3}$ que é o que acontece em diversos momentos do processo de desenvolvimento do capitalismo. Um importante fato histórico que demonstra a contradição entre Estado e economia são as legislações fabris inglesas que foram exaustivamente analisadas por Marx em $O$ Capital.

O papel co-determinante do Estado capitalista na formação da economia é explicitado por Marx no processo de acumulação originária do capital. Segundo Marx, uma das características do capitalismo é a necessidade de se ter a "ocupação simultânea de um número relativamente grande de assalariados no mesmo processo de trabalho [...] [Esta] coincide com a existência do próprio capital" (Marx 6, 252). Todavia, para o filósofo alemão a existência desse elevado número de trabalhadores assalariados não é um fato histórico acidental, muito menos surge espontaneamente com o desenvolvimento da economia capitalista. A economia que tem por base o capital dependeu, desde o princípio, de recursos externos a si para poder se consolidar e desenvolver.

No caso da formação dos trabalhadores assalariados foram necessárias as intervenções estatais que determinaram de maneira significativa a criação do proletariado. Tais intervenções, entretanto, só fizeram algum sentido quando já se tinha um grau de desenvolvimento econômico capitalista. De nada adiantaria o Estado intervir para a formação da classe de trabalhadores assalariados, se não houvesse unidades 
produtivas para acomodar pelo menos parte da força de trabalho. Portanto, a intervenção do Estado depende do desenvolvimento econômico e o desenvolvimento econômico, simultaneamente, da intervenção do Estado.

Por exemplo: para a constituição do vasto número de trabalhadores assalariados - base para o desenvolvimento econômico industrial, que é eminentemente capitalista - foi necessária a utilização da violência estatal (violência extraeconômica) que se observa nas legislações inglesas, que impõe a dissolução dos séquitos e a inserção dos trabalhadores no mercado de trabalho. A dissolução dos séquitos dependeu de um conjunto de fatores, entre eles, as ações diretas do Estado absolutista, que contribuíram para expropriar os camponeses, os quais tinham como único meio de produção e subsistência suas propriedades, transformando-os uma vez que estavam na condição de despossuídos, salvo de seu próprio corpo - em trabalhadores assalariados.

Como analisa Marx,

o prelúdio do revolucionamento, que criou a base do modo de produção capitalista, ocorreu no último terço do século XV e nas primeiras décadas do século XVI. Uma massa de proletários livres como os pássaros foi lançada no mercado de trabalho pela dissolução dos séquitos feudais [...]. [E] o poder real, ele mesmo um produto do desenvolvimento burguês, [acelerou] violentamente a dissolução desses séquitos [...] (Marx 6, p. 254).

O camponês expropriado - agora não mais na condição de camponês e sim de força de trabalho, com potencial para se tornar trabalhador assalariado - que se recusasse a submeter-se à grande indústria nascente na Inglaterra, já no século XVI, não poderia deixar de ter uma ocupação na produção. Isso porque Henrique VII e Henrique VIII implementaram legislações com o objetivo de eliminar os desocupados. Dessa forma, os camponeses foram forçados a se submeter ao mercado de trabalho. Como expõe Marx:

Os expulsos pela dissolução dos séquitos feudais e pela intermitente e violenta expropriação da base fundiária, esse proletário livre como os pássaros não podia ser absorvido pela manufatura nascente com a mesma velocidade com que foi posto no mundo. ${ }^{4}$ Por outro lado, os que foram bruscamente arrancados de seu modo costumeiro de vida não conseguiam enquadrar-se de maneira igualmente súbita na disciplina da nova condição. Eles se converteram em massas de esmoleiros, assaltantes, vagabundos [...] na maioria dos casos por força das circunstâncias. Daí ter surgido em toda a Europa ocidental, no final do século XV e durante todo o século XVI, uma legislação sanguinária contra a vagabundagem. [...] A legislação os tratava como criminosos 'voluntários' (Marx 6, pp. 265-266).

$\mathrm{Na}$ Inglaterra, tais legislações começaram no reinado de Henrique $\mathrm{VII}^{5}$ e se prolongaram até o século XVIII. No período de 1530, durante o reinado de Henrique VIII, a intervenção do aparelho jurídico-político para formação dos trabalhadores assalariados deu-se da seguinte maneira: todos os "esmoleiros velhos e incapacitados recebem licença para mendigar" (Marx 6, pp. 265-266). No entanto, aqueles que tivessem condições de trabalhar e não o fizessem eram condenados ao "açoitamento e encarceramento" (Marx 6, p. 265) e à execução. Vale dizer que, só no reinado de Henrique VIII, foram assassinadas cerca de 72 mil pessoas por causa dessa legislação $0^{6}$.

Concluindo Marx sobre a intervenção do aparelho jurídico-político para a formação dos trabalhadores assalariados: 
Assim, o povo do campo, tendo sua base fundiária expropriada à força e dela sendo expulso e transformado em vagabundos, foi enquadrado por leis grotescas [...] numa disciplina necessária ao sistema de trabalho assalariado, por meio do açoite, do ferro em brasa e da tortura. Não basta que as condições de trabalho apareçam num pólo como capital e no outro pólo como pessoas que nada têm para vender a não ser sua força de trabalho. Não basta também forçarem-nas a se venderem voluntariamente (Marx 6, pp. 265-266).

O que Marx põe em evidência, ao examinar os termos dessas leis, é que a economia, ou o simples advento de uma forma produtiva nova, não é suficiente por si mesma para se consolidar e se desenvolver. Para que se constitua o elevado número de trabalhadores assalariados - necessários ao surgimento e ao desenvolvimento do modelo econômico capitalista não são determinantes somente os novos desenvolvimentos econômicos industriais. Sem o violento processo político-jurídico - a intervenção do Estado - que obriga os indivíduos à inserção no embrionário mercado de trabalho, o sistema econômico capitalista não poderia chegar a existir.

A análise histórica realizada pelo pensador alemão sobre a constituição da massa de trabalhadores assalariados, principalmente na Inglaterra, com as legislações sanguinárias, permite perceber o quanto a economia capitalista (mesmo em seus momentos incipientes, nos quais ainda não é o modelo econômico predominante), depende da intervenção externa. Com a generalização do modelo produtivo capitalista, ou melhor, com a produção de mercadorias generalizadas por todos os ramos da atividade produtiva, a violência político-jurídica não é o principal método para a subordinação do trabalhador à dinâmica do trabalho assalariado por mais que ela ainda seja utilizada esporadicamente.
Com o pleno desenvolvimento da economia capitalista, o simples fato de se ter um elevado número de trabalhadores dispostos a ocupar uma vaga no mercado de trabalho já é suficiente para que a economia seja proclamada como de livre iniciativa. Dessa forma, em seu estágio mais avançado o capitalismo não depende tão frequentemente de medidas como as legislações sanguinárias.

Como observa Marx,

a violência extraeconômica direta é ainda, é verdade, empregada, mas apenas excepcionalmente. Para o curso usual das coisas, o trabalhador pode ser confiado às 'leis naturais da produção', isto é, à sua dependência do capital que se origina das próprias condições de produção, e por elas é garantida e perpetuada (Marx 6, p. 267).

O debate sobre a destruição dos séquitos feudais e a implementação das legislações sanguinárias faz compreender como, para Marx, a economia capitalista é determinada por legislações estatais. Outra dimensão que se visualiza ao explicitar-se essa dinâmica dos primórdios capitalistas é que o capitalismo para o filósofo alemão não é fruto de uma escolha livre dos indivíduos. O capitalismo é resultado de um violento processo de subsunção do trabalho ao capital. Vale dizer também que as relações econômicas capitalistas precisaram do

poder do Estado, a violência concentrada e organizada da sociedade, para ativar artificialmente o processo de transformação do modo feudal de produção em capitalista para abreviar a transição. A violência é a parteira de toda velha sociedade que está prenhe de uma nova. Ela mesma é uma potência econômica (Marx 6, p. 276). 
Isso mostra que o Estado para o teórico alemão é determinante para a estruturação, consolidação e permanência continuada do sistema capitalista. Esse papel determinante do Estado impossibilita reduzi-lo conceitualmente a superestrutura, pois suas ações pertencem à própria base do sistema do capital.

\section{REFERÊNCIAS BIBLIOGRÁFICAS}

1. ALTHUSSER, Louis. Idéologie et appareils idéologiques d'Etat. In Louis Althusser position. Paris: Editions Sociales. 1968.

2. ___ Aparelhos Ideológicos de Estado. Trad. Walter José Evangelista e Maria Laura Viveiro de Castro. Rio de Janeiro: Edições Graal. 1985.

3. __ Sobre a reprodução. Trad. Guilherme João de Freitas Teixeira. Rio de Janeiro: editora Vozes. 1999.

4. BOBBIO, Norberto. A Teoria das Formas de Governo. Trad. Sérgio Bath. Brasília: Editora Universidade de Brasília. 1992

5. MARX, Karl. Contribuição à crítica da economia política. Trad. Maria Helena Barreiro Alves. São Paulo: editora Martins Fontes. 1983.

6. __ O Capital. Trad. Regis Barbosa e Flávio R. Kothe. São Paulo: Nova Cultural, 1988.

7. MÉSZÁROS, István. Para além do Capital. Trad. Paulo Cezar Castanheira e Sérgio Lessa. São Paulo: Boitempo Editorial. 2002.

8. SMITH, Adam. A riqueza das nações. Trad. Alexandre Amaral Rodrigues e Eunice Ostrensky. São Paulo: Martins Fontes. 2003.

\section{THE TWO READINGS OF THE CAPITALISM IN MARX}

Abstract: The pyramidal understanding of the capitalist system in Marx, that is to say the conception which establish the design of the determination of the economic base over the superstructure (Rights, State and Ideologies) it was a wording fairly widespread by althusserian theory. Nevertheless, this understanding of pyramid of capitalism negligence the decisive role of the judicial apparatus-political on the economic processes. Thus, the intention is to show that the relationship between economic and State in Marx there is a co-determination, and not a unidirectional determination of the economy upon the State.

Keywords: Althusser, Marx, State, economy, determination, co-determination.

\section{NOTAS}

1. Segundo Althusser, em Marx a estrutura do capitalismo é "constituída por níveis ou instâncias, articuladas por uma determinação específica: [a determinação da infraestrutura sobre a superestrutura] a infraestrutura ou base econômica (unidade entre as forças produtivas e as relações de produção), e a superestrutura, que comporta em si dois níveis ou instâncias: o jurídico-político (o direito e o Estado) e o ideológico (as diferentes ideologias, religiosas, morais jurídicas, políticas etc.)" (Althusser 1, p. 74, tradução nossa).

2. Para Noberto Bobbio "Marx considera o Estado como [...] pura e simples superestrutura que reflete o estado das relações sociais determinadas pela base econômica" (Bobbio 4, p. 164).

3. A dialética entre Estado e economia capitalista fica impossibilitada com a concepção althusseriana de Estado capitalista. Para Althusser o Estado moderno é uma instância determinada pela base econômica. Ou seja, o Estado obedece invariavelmente à determinação da 'base econômica'. Dessa forma, em Althusser, o Estado não se contradiz com a economia.

4. Isso demonstra que o surgimento do proletariado, já em seus primeiros momentos, está na condição de excedente de força de trabalho, pois se a manufatura não absorve todos aqueles que estão se tornando a nova classe econômica, isto é, a dos trabalhadores assalariados, o que resta a eles é a desocupação permanente. Essa condição é extremamente desejável para uma indústria que desde o princípio tem por objetivo a redução dos salários dos que conseguiram um posto de trabalho. $O$ fato é que estes que possuem uma ocupação ficam permanentemente ameaçados de perder a ocupação que possuem, e, por isso, sujeitos a diminuir os salários, quando se tem em vista um elevado número de miseráveis que fariam a mesma atividade por um salário inferior.

5. Legislações análogas foram efetivadas na França, no reinado de Luis XVI. Como observa Marx, "na França, [...] em meados do século XVII se estabeleceu um reinado de vagabundos em Paris. Ainda nos primeiros anos de reinado de Luis XVI (ordenança de 13 de julho de 1777) todo homem com boa saúde de 16 a 60 anos, sem meios de existência e sem exercer uma profissão, devia ser mandado às galés. Analogamente o 
estatuto de Carlos V para os Países Baixos, de outubro de 1537, o primeiro edito dos Estados e Cidades da Holanda, de 19 de março de 1614, e o das Províncias Unidas de 25 de julho de 1649 etc." (Marx 6, pp. 266-267).

6. As legislações de Eduardo VI, ou melhor, em "um estatuto de seu primeiro governo" (Marx 6, pp. 265-266), de 1547, determinava que "se alguém se recusa a trabalhar, deverá ser condenado a se tornar escravo da pessoa que o denunciou como vadio" (Marx 6, pp. 265-266). O denunciante passava, então, a ter o direito de forçar o denunciado "a qualquer trabalho, mesmo o mais repugnante, por meio do açoite e de corrente" (Marx 6, pp. 265-266). Caso o condenado por vagabundagem não cumprisse essas imposições passaria a ser compreendido como um traidor e, por conseguinte, seria "executado como traidor do Estado" (Marx 6, pp. 265-266). No reinado de Elisabeth, no ano de 1572, a intervenção do aparelho jurídico-político no processo de formação do trabalhador assalariado deu-se nos seguintes termos: "esmoleiros sem licença e com mais de 14 anos de idade devem ser duramente açoitados e terão a orelha esquerda marcada a ferro, caso ninguém os queira tomar a serviço por dois anos" (Marx 6, pp. 265-266), e se tal criminoso não realizar sua inserção no mercado de trabalho até os dezoito anos, este deveria "ser executado [...] sem perdão, como traidor do Estado" (Marx 6, pp. 265-266). No período do governo de Jaime I, o aparelho jurídicopolítico também exerce sua contribuição no processo de formação dos trabalhadores assalariados, estabelecendo que a pessoa que "perambule e mendigue será declarada um malandro e vagabundo" (Marx 6, pp. 265-266). Qualquer pessoa tinha o direito de denunciar esse tipo de crime e os juízes de paz estavam "autorizados a mandar açoitálos publicamente" (Marx 6, pp. 265-266). Nesse governo, os condenados pelo crime de vagabundagem, na primeira vez, eram "encarcerados por seis meses, na segunda por dois anos" (Marx 6, pp. 265-266). E, além do cárcere, esses prisioneiros deveriam "ser açoitados tantos e tantas vezes quanto os juízes de paz" (Marx 6, pp. 265-266) considerassem adequado para a punição de tal crime.

\section{PRÓ-AO-CONTRA, VÁCUO E MATERIALIDADE DA IDEOLOGIA. ENSAIO SOBRE FRAGMENTOS DE ALTHUSSER E PASCAL ${ }^{1}$}

Antônio Herci Ferreira Júnior

Aos moradores da Comunidade Pinheirinho:

assujeitados e sujeitos ideológicos.

Resumo: No artigo “A única tradição materialista”, Althusser $(2,4,5)$ apresenta alguns fundamentos de sua teoria da materialidade da ideologia referenciados explicitamente em Pascal: 1) o pró-ao-contra e a condição material da verdade (que pode tomá-la por contrária sem contraditório); 2) a intuição [sic] do vácuo como assunto filosófico (postulação capaz de negar o substrato para a matéria).

Caracteriza a produção ideológica como um trabalho humano capaz de incorporar as contradições de classe e impregnar diretamente os aparatos ideológicos e postula a necessidade da formulação de uma doutrina dogmática, para combater numa arena de dogmáticos. Apresenta-se aqui uma das ferramentas centrais de tal teoria: o aparato dos corpos - que também tributa a Pascal - efetivamente uma forma de expressar a materialidade da ideologia.

Palavras-chave: aparato dos corpos; transferência; contratransferência; materialismo.

Assim, não podendo fazer com que o que é justo fosse forte, fez-se com que o que é forte fosse justo.

(Pascal 9, §298|103)

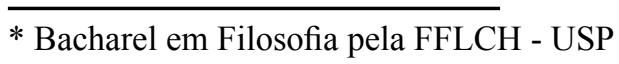

